\title{
Article \\ Effects of Curing Conditions and Supplementary Cementitious Materials on Autogenous Self-Healing of Early Age Cracks in Cement Mortar
}

\author{
Mian Luo ${ }^{1,2,3, *}$, Kang Jing ${ }^{1,2}$, Jingquan Bai ${ }^{1,2}$, Ziqi Ding ${ }^{1,2}$, Dingyi Yang ${ }^{1,2}$, Haoliang Huang ${ }^{4, *}$ and \\ Yongfan Gong 1,2 (D)
}

check for updates

Citation: Luo, M.; Jing, K.; Bai, J.; Ding, Z.; Yang, D.; Huang, H.; Gong, Y. Effects of Curing Conditions and Supplementary Cementitious

Materials on Autogenous

Self-Healing of Early Age Cracks in Cement Mortar. Crystals 2021, 11, 752. https://doi.org/10.3390/cryst11070752

Academic Editors: Cesare Signorini, Antonella Sola, Sumit Chakraborty and Valentina Volpini

Received: 9 June 2021

Accepted: 24 June 2021

Published: 27 June 2021

Publisher's Note: MDPI stays neutral with regard to jurisdictional claims in published maps and institutional affiliations.

Copyright: (c) 2021 by the authors Licensee MDPI, Basel, Switzerland. This article is an open access article distributed under the terms and conditions of the Creative Commons Attribution (CC BY) license (https:/ / creativecommons.org/licenses/by/ $4.0 /)$.
1 College of Civil Science and Engineering, Yangzhou University, Yangzhou 225127, China; www.2910252115@outlook.com (K.J.); baijingquan2021@163.com (J.B.); dzq960825@163.com (Z.D.) ydy1991@163.com (D.Y.); yfgong@yzu.edu.cn (Y.G.)

2 Research Institute of Green Building Materials, Yangzhou University, Yangzhou 225127, China

State Key Laboratory of Green Building Materials, Beijing 100024, China

4 School of Materials Science and Engineering, South China University of Technology, Guangzhou 510641, China

* Correspondence: luomian@yzu.edu.cn (M.L.); huanghaoliang@scut.edu.cn (H.H.)

\begin{abstract}
The autogenous healing potential of cement-based materials is affected by multiple factors, such as mix composition, crack width, pre-cracking age and external environmental conditions. In this study, the effects of curing conditions and supplementary cementitious materials (SCMs) on autogenous self-healing of early age cracks in cement mortar were investigated. Three curing conditions, i.e., standard curing, wet-dry cycles and incubated in water, and two SCMs, i.e., fly ash (FA) and blast furnace slag (BFS) with various contents (cement replacement ratio at $0 \%, 20 \%$, and $40 \%$ ) were examined. A single early age crack (pre-cracking age of 3 days) with a width of 200 300 $\mu \mathrm{m}$ was generated in cylindrical mortar specimens. Autogenous crack self-healing efficiency of mortar specimens was evaluated by performing a visual observation and a water permeability test. Moreover, microstructure analysis (XRD, SEM and TG/DTG) was utilized to characterize the healing products. The results indicated that the presence of water was essential for the autogenous self-healing of early age cracks in cement mortar. The efficiency of self-healing cracks was highest in specimens incubated in water. However, no significant self-healing occurred in specimens exposed to standard curing. For wet-dry cycles, a longer healing time was needed to obtain good selfhealing compared to samples incubated in water. SCMs type and content significantly affected the autogenous self-healing ability of early age cracks. The self-healing efficiency of early age cracks decreased with increases in FA and BFS content. BFS mortars exhibited greater recovery in relation to water penetration resistance compared to the reference and FA mortars. Almost the same regain of water tightness and a lower crack-healing ratio after healing of 28 days in FA mortars were observed compared to the reference. The major healing product in the surface cracks of specimens with and without SCMs was micron-sized calcite crystals with a typical rhombohedral morphology.
\end{abstract}

Keywords: crack; autogenous self-healing; cement mortar; curing conditions; supplementary cementitious materials (SCMs)

\section{Introduction}

The presence of cracks is inevitable in concrete structures and may reduce concrete's durability due to the easy ingress of aggressive substances [1-4]. Fortunately, an autogenous crack-healing phenomenon has been found under the right conditions in concrete, which is mainly due to the ongoing hydration of unhydrated cement particles and the formation of calcium carbonate precipitation [5-7]. However, the autogenous healing capacity of concrete itself is limited in most instances [8,9]. Therefore, in recent years, enhancing the self-healing ability of concrete has received increasing attention. 
In reported studies, various methods have been proposed to promote the self-healing efficiency of concrete [10]. These methods can be divided broadly into two categories [9]. The first method, defined as autonomic healing, promotes self-healing efficiency by adding additional self-healing agents into a concrete matrix, such as microcapsules containing adhesives [11], bacteria [12-15] and active mineral additives [16,17]. The second method, defined as autogenic or autogenous healing, relies on the self-healing ability of a concrete matrix itself by optimally designing the mix composition [18], creating suitable environmental conditions [19] and using fibers to constrain the width of potential cracks [20,21]. Despite lower healing efficiency compared to autonomic healing, autogenous healing exhibits advantages in terms of cost and compatibility, as no other components that usually are not found in concrete are introduced. Therefore, it is important to develop cement-based materials with robust autogenous healing.

Fly ash (FA) and blast furnace slag (BFS) are widely utilized as supplementary cementitious materials (SCMs) in modern concrete [22,23]. The partial replacement of cement with SCMs can save costs, decrease $\mathrm{CO}_{2}$ emissions and improve the performance of concrete. Recently, several studies [18,24-30] have reported that incorporating SCMs could improve the autogenous crack healing of concrete. Van Tittelboom et al. [18] concluded that cement replacement by blast furnace slag or fly ash improved autogenous healing by enhancing further hydration, and blast furnace slag showed a better effect than fly ash. Sahmaran et al. [24] also found that the type of supplementary cementitious materials greatly affected the self-healing capability of cementitious composites. Huang et al. [25] reported that slag cement paste exhibited higher autogenous healing potential compared to Portland cement paste. Qiu et al. [26] investigated the effect of slag content $(0 \%, 30 \%$ and $60 \%$ cement replacement) on the autogenous healing behavior of engineered cementitious composite (ECC) at a pre-cracking age of 40 days. The results indicated that replacing cement with blast furnace slag at 30\% exhibited a better crack width reduction compared to the $0 \%$ and $60 \%$ replacement. Şahmaran et al. [28] and Termkhajornkit et al. [29] pointed out that the self-healing ability of cement-based materials increased with fly ash content.

It is notable that, in the above reported studies, most of specimens used to evaluate autogenous healing potential were pre-cracked at an age of 28 days or later. Considering that cement-based materials easily crack at an early age, more information is needed regarding the autogenous self-healing of early age cracks in cement-based materials containing supplementary cementitious materials. Therefore, in this study, so as to better understand the self-healing behavior of cement-based materials containing supplementary cementitious materials, the effects of various supplementary cementitious materials (FA and BFS) on the autogenous self-healing of early age cracks (pre-cracking age of 3 days) in cement mortar were investigated. Moreover, autogenous healing is also greatly influenced by exposure to environmental conditions [31-33]. The influence of curing conditions on autogenous self-healing was also investigated. Three curing conditions (standard curing, wet-dry cycles and incubated in water) that are common exposure environments in the field of engineering were considered. The best one among the three curing conditions for autogenous healing was used for subsequent research in cement mortar containing supplementary cementitious material. Autogenous crack self-healing efficiency was evaluated by performing a visual observation and a water permeability test. Moreover, X-ray diffraction (XRD), scanning electron microscopy (SEM) and thermogravimetry (TG/DTG) were utilized to characterize the healing products. The effect mechanisms of curing conditions, as well as the influence of supplementary cementitious material, on autogenous self-healing were further addressed.

\section{Materials and Methods}

\subsection{Materials and Specimen Preparation}

Portland cement, river sand (fineness modulus of 2.1) and tap water were mixed to prepare mortar mixtures. The water-to-cement ratio (W/C) was 0.5 and the sand-tocement mass ratio was 3. Two cement types (P.O 42.5 and P.I 42.5) were used. For mortar 
specimens used to investigate the effect of curing conditions on autogenous crack selfhealing, P.O 42.5 cement was used. For mortar specimens used to investigate the effect of supplementary cementitious material on autogenous crack self-healing, P.I 42.5 cement, which only contains Portland clinker, was used to avoid the influence of supplementary cementitious materials in the cement itself. Although some research results [18] show that the types of cement may affect the degree of hydration and self-healing ability, they do not affect the discussion of test results in the paper because curing conditions and supplementary cementitious materials were the main factors considered in this study. Portland cement was partially replaced by fly ash (FA) or blast furnace slag (BFS), and two SCMs (FA and BFS) with various contents (cement replacement ratio at $0 \%, 20 \%$ and $40 \%$ ) were considered. The mixing proportions of the specimens are shown in Table 1. Chemical compositions of Portland cement, fly ash (FA) and blast furnace slag (BFS) are shown in Table 2. The polypropylene fibers with a diameter of $31 \mu \mathrm{m}$ and a length of $12 \mathrm{~mm}$ were utilized to keep the specimens intact after being pre-cracked. The mixtures were poured into cylindrical molds with a diameter of $10 \mathrm{~cm}$ and a height of $2.5 \mathrm{~cm}$. The specimens were unmolded after $24 \mathrm{~h}$ and subsequently stored in a standard curing room $\left(20 \pm 2{ }^{\circ} \mathrm{C}\right.$ and $>95 \% \mathrm{RH}$ ) for further curing.

Table 1. Mixing proportions of cement mortars (FA and BFS are short for fly ash and blast furnace slag, respectively).

\begin{tabular}{cccccc}
\hline Mix. & Cement (g) & FA (g) & BFS (g) & Sand $(\mathbf{g})$ & Water $(\mathbf{g})$ \\
\hline Reference & 450 & $/$ & $/$ & 1350 & 225 \\
20FA & 360 & 90 & $/$ & 1350 & 225 \\
40FA & 270 & 180 & $/$ & 1350 & 225 \\
20BFS & 360 & $/$ & 90 & 1350 & 225 \\
40BFS & 270 & $/$ & 180 & 1350 & 225 \\
\hline
\end{tabular}

Table 2. Chemical compositions of Portland cement, fly ash (FA) and blast furnace slag (BFS).

\begin{tabular}{ccccc}
\hline Components (wt.\%) & P.O 42.5 & P.I 42.5 & FA & BFS \\
\hline $\mathrm{SiO}_{2}$ & 22.94 & 17.56 & 55.81 & 29.51 \\
$\mathrm{CaO}$ & 59.77 & 68.80 & 4.48 & 42.55 \\
$\mathrm{Al}_{2} \mathrm{O}_{3}$ & 6.95 & 3.41 & 27.31 & 12.21 \\
$\mathrm{SO}_{3}$ & 3.24 & 2.69 & 1.07 & 2.24 \\
$\mathrm{Fe}_{2} \mathrm{O}_{3}$ & 3.98 & 3.64 & 5.81 & 0.30 \\
$\mathrm{MgO}$ & 1.89 & 2.46 & 0.91 & 11.23 \\
Others & 1.23 & 1.44 & 3.93 & 1.91 \\
\hline
\end{tabular}

\subsection{Creation of Crack}

Before evaluating the autogenous crack self-healing efficiency of the mortar specimen, it was necessary to make cracks that met the test requirements. In this study, a new crack production method was developed; with this method, it is easy to control crack width and shape (Figure 1). At 3 days of age, the cylindrical mortar specimen was taken out from the curing room and tightly wrapped along the side of the specimen by the steel hose clamp. Then, the splitting tensile strength test (Figure 1) was used to generated cracks in the specimens. Crack width was controlled at 200 300 $\mu \mathrm{m}$ by adjusting the tightness of the hose clamp. 


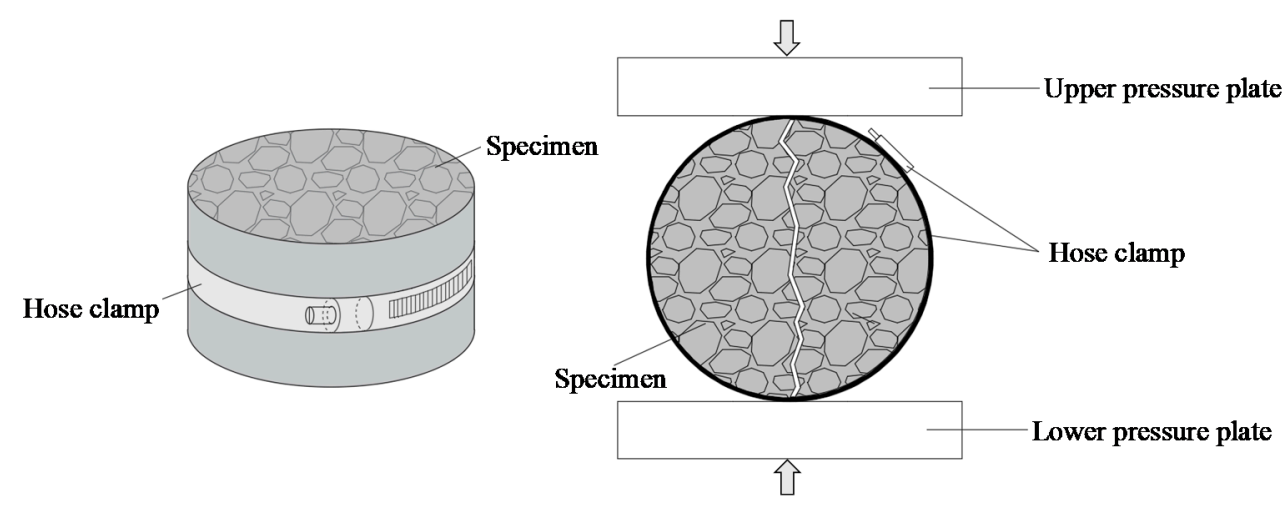

Figure 1. Creation of crack in mortar specimen.

\subsection{Self-Healing Curing Conditions}

To investigate the effect of curing conditions on autogenous crack self-healing in the cement mortar specimens, pre-cracked specimens were placed in three curing conditions: (a) standard curing $(>95 \% \mathrm{RH})$; (b) wet-dry cycles (for each cycle, the cracked specimen was incubated in water for $12 \mathrm{~h}$ and then taken out to air dry for $12 \mathrm{~h}$ ); (c) submerged in water. After healing for $0,3,14,28$ and 56 days, crack-healing quantification of specimens was conducted by a stereo optical microscope and a water permeability test. To investigate the effect of supplementary cementitious material on autogenous crack self-healing, all pre-cracked specimens were submerged in water for crack-healing quantification.

\subsection{Crack-Healing Quantification}

\subsubsection{The Crack-Healing Ratio}

The closure of surface cracks on the specimen during the self-healing process was observed by a stereo optical microscope (LIOO, Attendorn, Germany). Crack self-healing efficiency was evaluated based on the change in crack area before and after healing. Crack area was measured based on the number of pixels in the recorded images through Image-J software. The crack-healing ratio is defined as the Equation (1), where $A_{0}$ and $A_{t}$ represent the crack area before and after healing for time $t$, respectively. For more details, see our earlier papers [14,34].

$$
\text { The crack healing ratio }=\frac{A_{0}-A_{t}}{A_{0}} \times 100 \%
$$

\subsubsection{Water Permeability Test}

A constant water head permeability test (Figure 2) was carried out to obtain the initial water permeability coefficient of the specimens $k_{0}(\mathrm{~cm} / \mathrm{s})$, as well as the water permeability coefficient of the specimens after healing for a certain time $k_{t}(\mathrm{~cm} / \mathrm{s})$. For the detailed calculation of the water permeability coefficient, please refer to our previous research [34]. In addition, the relative permeability coefficient was calculated to evaluate the self-healing efficiency of mortar specimens according to Equation (2).

$$
\text { The relative permeability coefficient }=\frac{k_{t}}{k_{0}}
$$




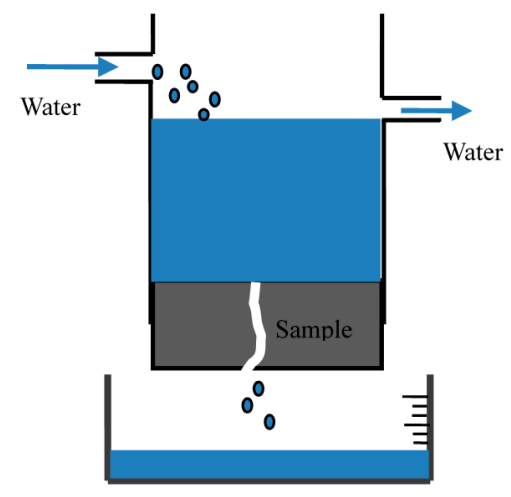

Figure 2. Setup of water permeability test.

\subsection{Characterization of Reaction Products of Self-Healing Formed in Early Age Cracks}

After crack-healing quantification, the healing products that formed at the surface cracks of the mortar specimens were collected and analyzed with XRD, SEM and TG/DTG, respectively. XRD analyses adopted the D8-Advance X-ray diffractometer produced by the Bruker-AXS company (Karlsruhe, Germany). Powder samples were scanned at diffraction angle $2 \theta$ from $5^{\circ}$ to $90^{\circ}$. For TG/DTG analysis, powder samples were heated from room temperature to $800{ }^{\circ} \mathrm{C}$ at a rate of $10^{\circ} \mathrm{C} / \mathrm{min}$ in an $\mathrm{N}_{2}$ atmosphere.

\section{Results and Discussion}

\subsection{Crack-Healing Quantification under Different Curing Conditions}

\subsubsection{The Crack-Healing Ratio}

Figure 3 shows that the closure of surface cracks in mortar specimens under different curing conditions and after different healing times. It can be seen that no visual healing was observed in specimens exposed to standard curing, even after a healing period of 56 days. However, complete crack sealing was found in specimens incubated in water for 14 days. For specimens under wet-dry cycles, only partial crack filling was showed.

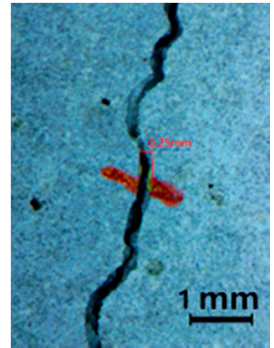

$0 \mathrm{~d}$

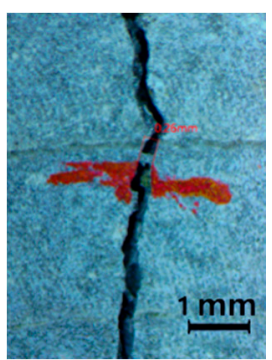

$0 \mathrm{~d}$

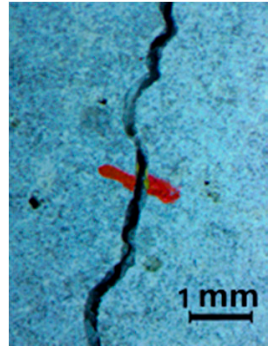

$3 d$

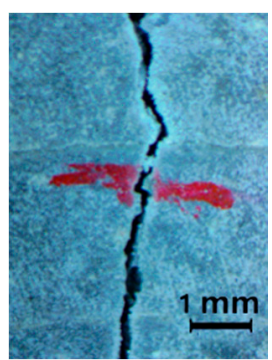

$3 d$

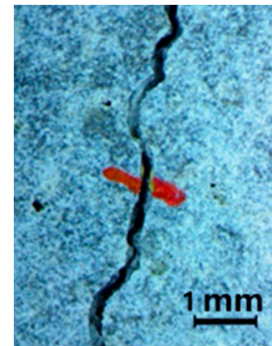

$14 \mathrm{~d}$

(a)

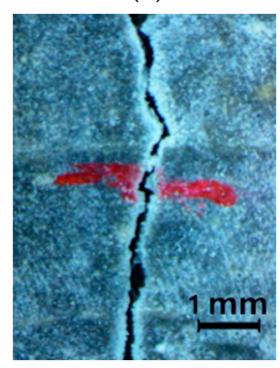

$14 \mathrm{~d}$

(b)

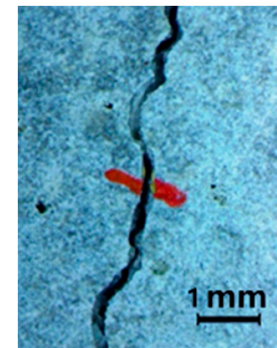

$28 \mathrm{~d}$

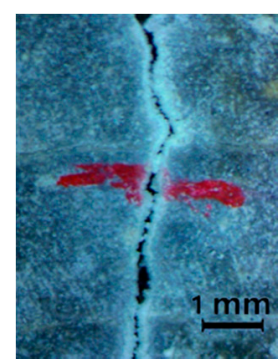

$28 \mathrm{~d}$

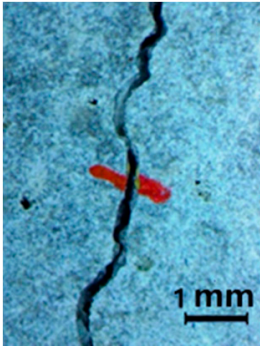

$56 \mathrm{~d}$

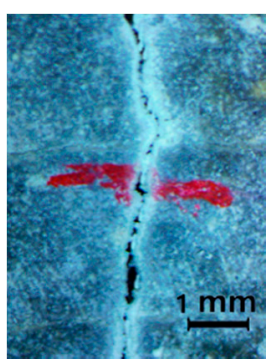

$56 \mathrm{~d}$

Figure 3. Cont. 


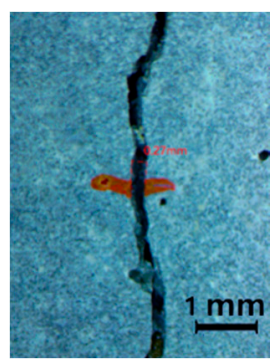

$0 \mathrm{~d}$

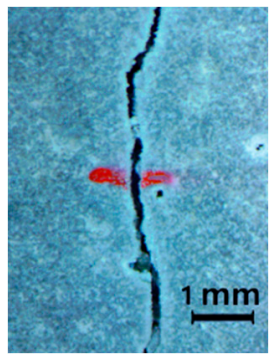

$3 d$

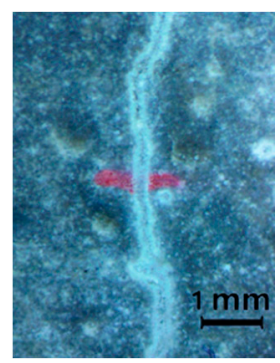

$14 \mathrm{~d}$

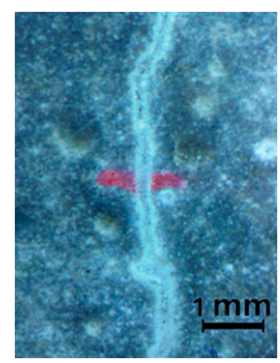

$28 \mathrm{~d}$

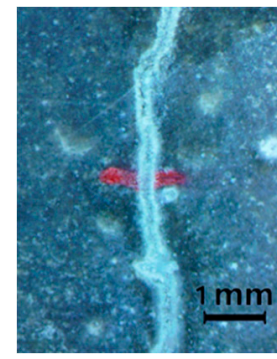

$56 \mathrm{~d}$

(c)

Figure 3. The closure of surface cracks in specimens under different curing conditions after different healing times: (a) standard curing ( $>95 \% \mathrm{RH})$; (b) wet-dry cycles; (c) submerged in water ( $d$ denotes days).

To quantitatively assess self-healing efficiency, the images of surface cracks in mortar specimens monitored by a stereo optical microscope were processed using Image-J software (National Institutes of Health, Bethesda, MD, America) (Figure 4); the crack-healing ratio was obtained according to Equation (1), as shown in Figure 5. The crack-healing ratio was highest in specimens incubated in water, followed by wet-dry cycles; standard curing was the lowest ratio. It was noted that the crack-healing ratio of specimens under wet-dry cycles gradually increased with the extension of healing time, although these exhibited a lower crack-healing ratio than those specimens incubated in water. The autogenous selfhealing of cracks is mainly attributable to the hydration of unhydrated cement particles and the precipitation of calcium carbonate. In the opening of the crack, the main mechanism of self-healing may be attributable to the precipitation of calcium carbonate. Inside the crack, the ongoing hydration of unreacted cement may be dominant because the carbonization process is limited; this is because carbon dioxide struggles to enter deep into the crack, especially in the specimens incubated in water. For specimens incubated in water, adequate water supply is beneficial to the further hydration of unhydrated cement particles and the precipitation of calcium carbonate in the surface crack due to more $\mathrm{Ca}^{2+}$ dissolution emanating from said crack. Carbon dioxide from the air can dissolve in water to form carbonates and produce calcium carbonate precipitations when in contact with calcium ions in the mouth of the crack. For specimens under wet-dry cycles, in each cycle, the cracked specimen was incubated in water for $12 \mathrm{~h}$ and then taken out to air dry for $12 \mathrm{~h}$. More carbonate ions can be formed because carbon dioxide is more likely to reach the crack opening while being air dried. However, less hydration of cement particles occurred and there was less $\mathrm{Ca}^{2+}$ supply at the same healing time. The crack-healing ratio for wet-dry cycle specimens depends on the combined result of the above two aspects. Therefore, although curing in water may inhibit carbon dioxide supply, specimens submerged in water exhibited a higher crack-healing ratio than that of specimens under wet-dry cycles (Figure 5). No significant self-healing (less than 10\% of crack-healing ratio) occurred in specimens exposed to standard curing due to lack of water. Calcium carbonate precipitation struggles to form, and the healing of the cracks can only be attributed to the ongoing hydration of partial unreacted cement particles in high humidity conditions. 


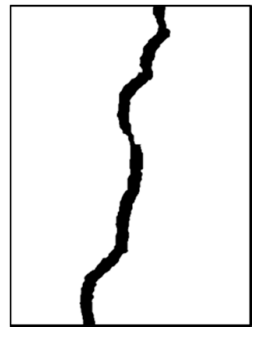

$0 \mathrm{~d}$

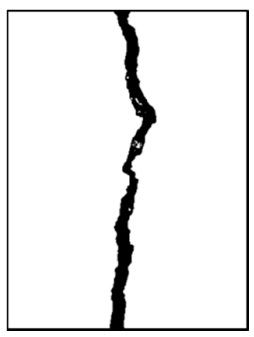

$0 \mathrm{~d}$

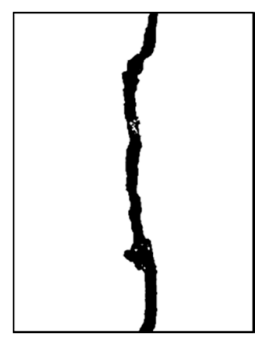

$0 \mathrm{~d}$

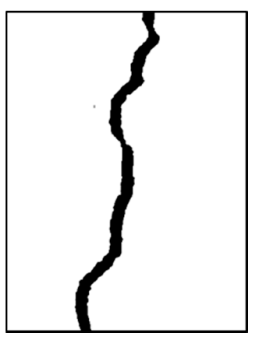

$3 \mathrm{~d}$

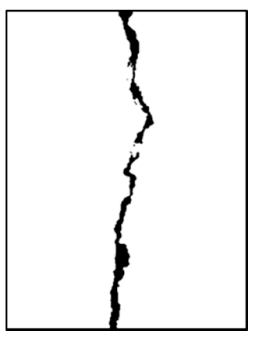

$3 \mathrm{~d}$

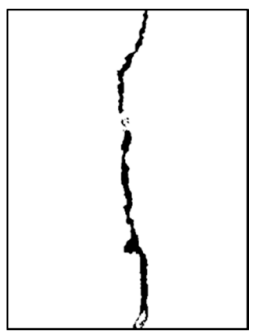

$3 \mathrm{~d}$

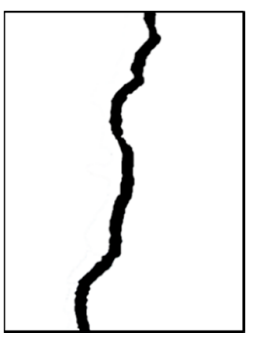

$14 \mathrm{~d}$

(a)

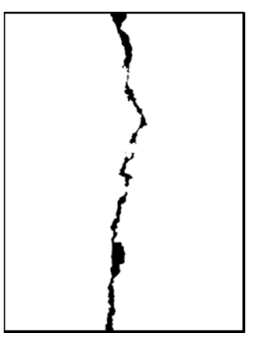

$14 \mathrm{~d}$

(b)

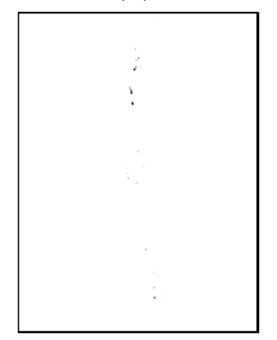

$14 \mathrm{~d}$

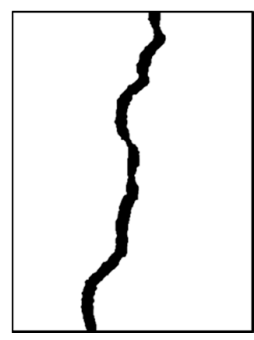

$28 \mathrm{~d}$

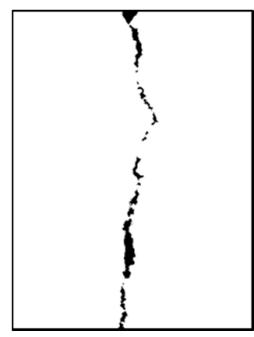

$28 \mathrm{~d}$

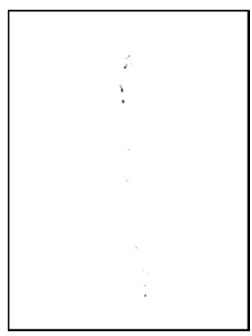

$28 \mathrm{~d}$

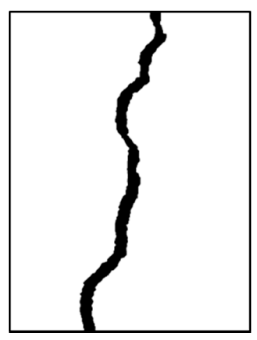

$56 \mathrm{~d}$

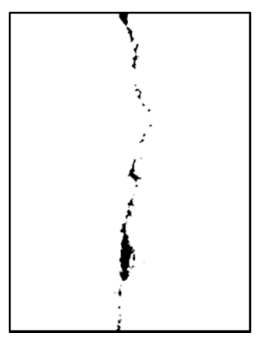

$56 \mathrm{~d}$

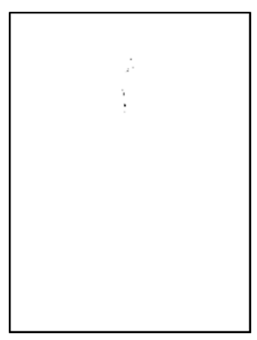

$56 \mathrm{~d}$

(c)

Figure 4. Binarization images of surface cracks in specimens under different curing conditions after different healing times: (a) standard curing (>95\% RH); (b) wet-dry cycles; (c) submerged in water $(d$ denotes days).

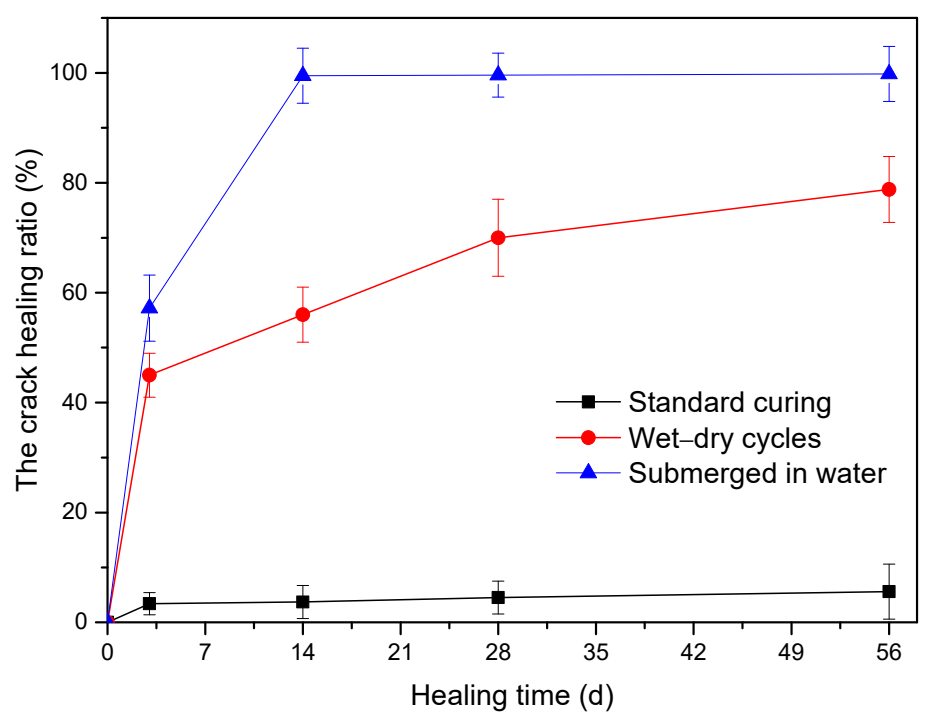

Figure 5. Crack-healing ratio of specimens under different curing conditions after different healing times ( $d$ denotes days). 


\subsubsection{Water Permeability Test}

The measurements of crack width, crack area and water permeability were widely used to characterize the healing effect $[9,14,31,32]$. In Section 3.1.1, the crack-healing ratio based on a reduction in crack area was used to visualize the self-healing of surface cracks, but it could not reflect the internal healing effect. Therefore, the water permeability test, which is not only related to the sealing of surface cracks but also to the healing of internal cracks, was conducted to further evaluate the self-healing efficiency of the cracks. Figure 6 shows the change in relative permeability of specimens under different curing conditions and healing times. The result is consistent with that of the crack-healing ratio. The specimens incubated in water and under wet-dry cycles exhibited a better recovery in water penetration resistance compared to specimens exposed to standard curing. An obvious decline in relative permeability was observed in specimens incubated in water and under wet-dry cycles, which indicated that the presence of water is essential for the autogenous self-healing of early age cracks in cement mortar. In addition, it is worth noting that, although the crack-healing ratio for wet-dry cycles specimens was obviously inferior to that of specimens incubated in water, the change in relative permeability coefficient for wet-dry cycle specimens was similar to that of specimens incubated in water. This may be attributed to more healing products being formed in internal cracks for specimens under wet-dry cycles.

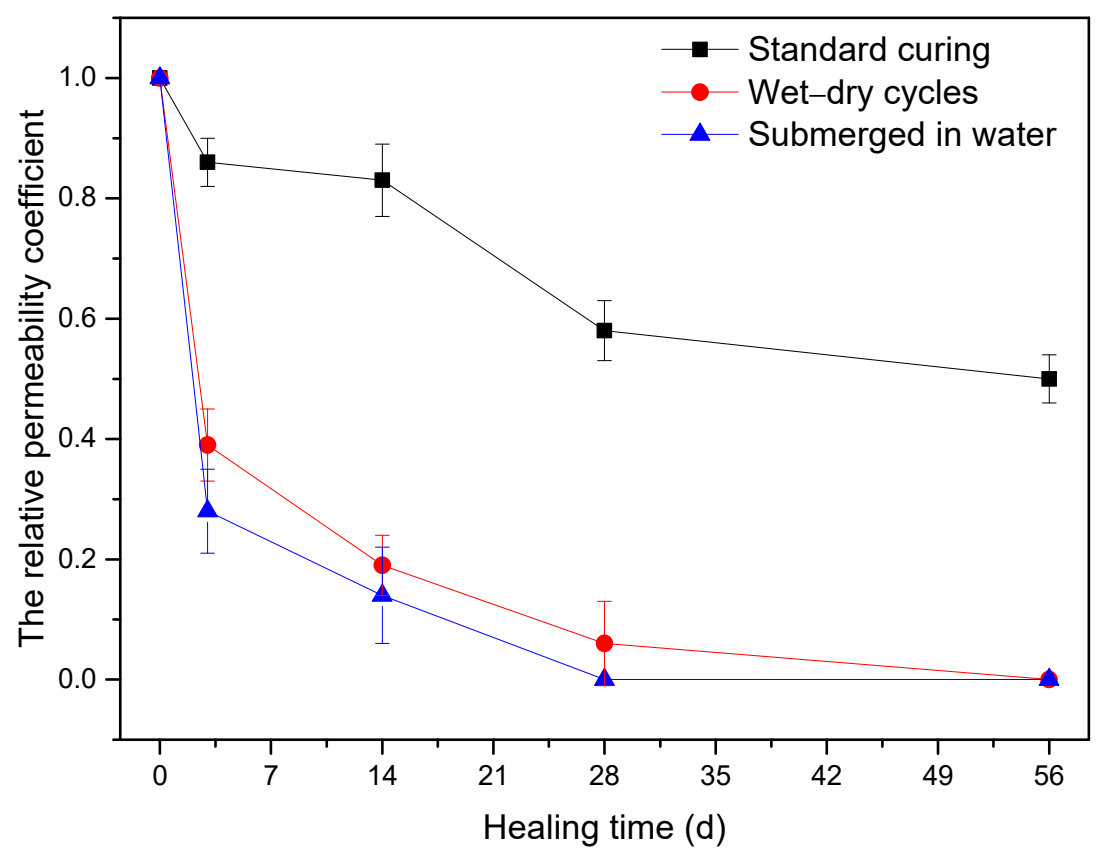

Figure 6. Relative permeability coefficient changes with healing time under different curing conditions ( $d$ denotes days).

\subsection{Crack-Healing Quantification under Different Supplementary Cementitious Materials \\ 3.2.1. The Crack-Healing Ratio}

The crack-healing ratios of mortar specimens containing different SCMs with various content are shown in Figure 7. As can be seen, the addition of SCMs changed the autogenous self-healing behavior of surface cracks in mortar specimens. The influence of SCMs on the crack-healing ratio is related to their type and content. For BFS specimens, the crack-healing ratio decreased with the increase in BFS content. Moreover, 20BFS exhibited a higher crack-healing ratio compared to the reference; however, 40BFS showed a lower crack-healing ratio compared to the reference. For FA specimens, the crack-healing ratio also decreased with the increase in FA content. However, both 20FA and 40FA showed a lower crack-healing ratio compared to the reference after a healing period of 28 days. In 
general, it is not beneficial to replace cement with FA or BFS for the self-healing of early age surface cracks (pre-cracking age of 3 days) in mortar specimens (except 20BFS specimen). Comparing FA with BFS, at a given content of $20 \%$, BFS specimens exhibited a higher crack-healing ratio compared to FA specimens. However, FA specimens showed a higher crack-healing ratio compared to BFS specimens when the content was increased to $40 \%$.

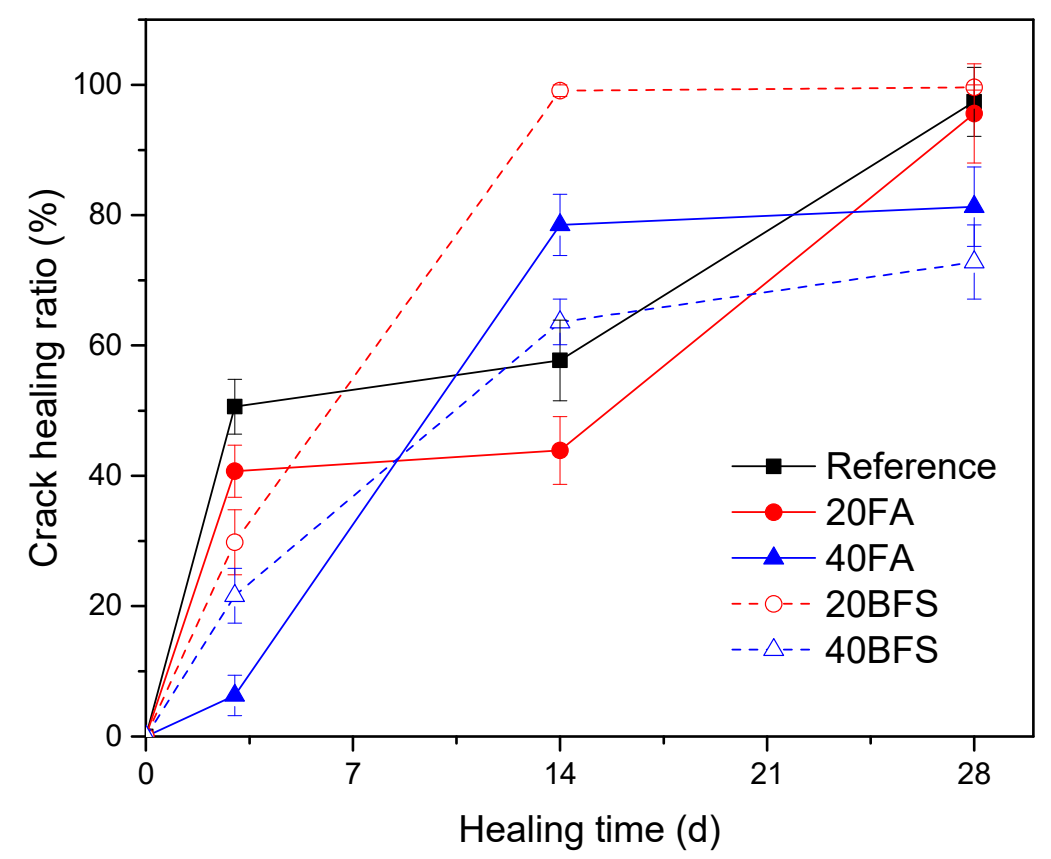

Figure 7. Crack-healing ratio of specimens containing different SCMs with various content ( $d$ denotes days).

The autogenous self-healing of surface cracks is mainly attributable to two mechanisms: (1) ongoing hydration of unreacted cement or SCMs particles; (2) formation of calcium carbonate precipitation. The crack-healing ratio of specimens with SCMs depends on the coupled effect of the abovementioned two aspects. In this study, early age cracks (pre-cracking age of 3 days) were generated. After cracking, specimens with SCMs had more unreacted binder particles due to slower hydration of FA or BFS. The ongoing hydration of unreacted binder particles is beneficial to promote self-healing of the crack. However, the ongoing hydration of FA or BFS needs to be activated by $\mathrm{Ca}(\mathrm{OH})_{2}$, which is mainly attributed to cement hydration. In specimens with SCMs, the portlandite content is lower than that of the referenced specimens due to less cement composition and the partial consumption of portlandite by the hydration reaction of FA or BFS [18,27]. The reduction in $\mathrm{Ca}(\mathrm{OH})_{2}$ greatly influenced the formation of calcium carbonate precipitations and ongoing hydration of FA or BFS at the surface cracks. When the formation of calcium carbonate precipitation is the main mechanism, FA or BFS may not be good for the autogenous self-healing of surface cracks. It was noted that 20BFS exhibited a higher crack-healing ratio compared to the reference. This is because that there are still large amounts of unhydrated cement particles in early cracking specimens when the BFS content is low; further hydration of unreacted cement particles provides additional $\mathrm{Ca}(\mathrm{OH})_{2}$ to promote the hydration of BFS and the formation of calcium carbonate precipitation at the crack's surface. The 40FA specimen exhibited a higher crack-healing ratio compared to the 40BFS specimens, which may be attributed to the lower hydration activity of FA, resulting in more $\mathrm{Ca}(\mathrm{OH})_{2}$ for calcium carbonate formation. 


\subsubsection{Water Permeability Test}

Figure 8 shows the change in relative permeability of specimens containing different $\mathrm{SCMs}$ with various content over different healing times. The changing trend of regaining water tightness is different from that of the crack-healing ratio. This is because regaining the water tightness of the pre-cracked mortar specimens is not only related to the sealing of surface crack but also to the healing of internal cracks. For BFS mortars, both 20BFS and 40BFS showed better regaining abilities of water tightness compared to the reference specimens. Although a lower crack-healing ratio after healing for 28 days was observed for 40BFS mortar compared to the reference, the higher regaining capacity for water tightness may be attributed to more healing products being formed in internal cracks due to the ongoing hydration of more unreacted BFS particles. As for FA mortars, the regaining of water tightness declined with the increasing FA content. This is because that the hydration activity of FA is low and not enough calcium hydroxide can be utilized to activate the hydration of unreacted FA particles in internal cracks for mortars with a high content of FA. Moreover, it was noted that 20FA and 40FA exhibited a lower decline in the relative permeability coefficient after healing for 3 days compared to the reference, but almost the same decline in the relative permeability coefficient after healing for 28 days was observed compared to the reference. This is because unreacted FA particles in the crack cannot be activated in the early healing process but can be activated as the healing time increases. It also can be found that BFS mortars exhibited a better regaining of water tightness compared to FA mortars; this is due to their higher hydration activity and $\mathrm{CaO}$ content for slag.

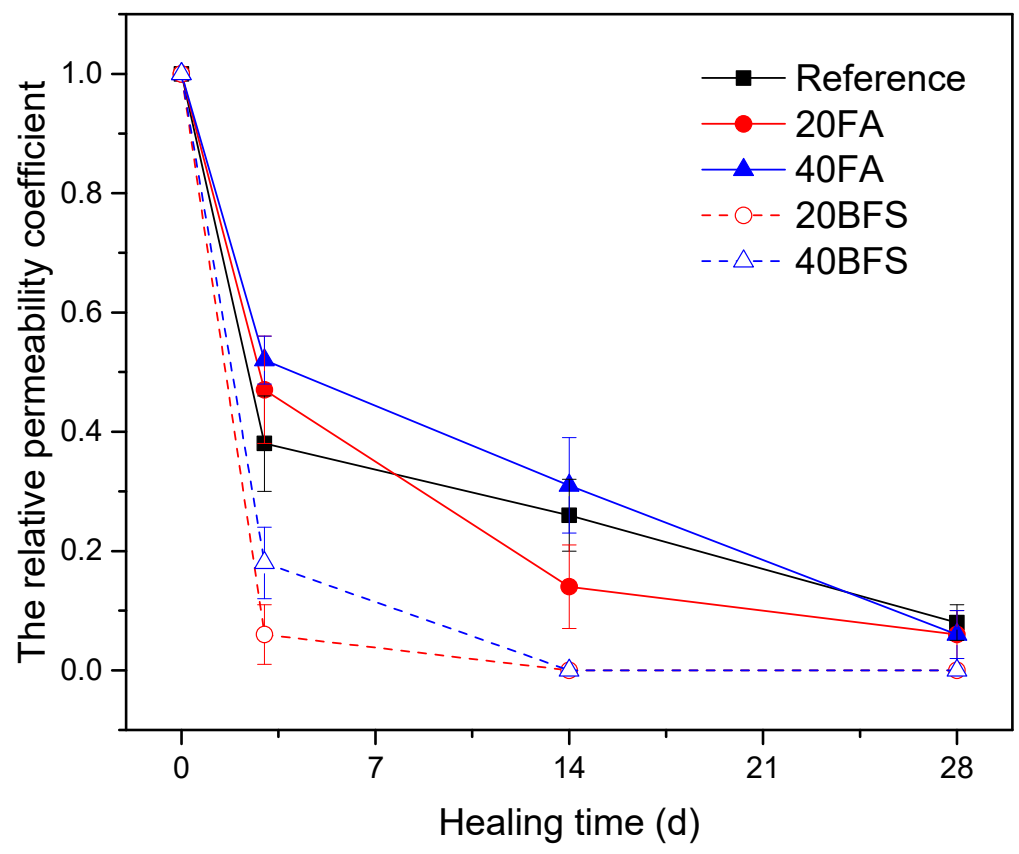

Figure 8. Relative permeability coefficient of specimens containing different SCMs with various content ( $d$ denotes days).

\subsection{Mineralogy of Reaction Products of Self-Healing in Early Age Cracks}

After crack-healing quantification, XRD, SEM and TG/DTG were conducted on the healing products scraped from the healed surface cracks of the referenced specimens, as well as the specimens that contained different supplementary cementitious materials (SCMs). Figure 9 shows the XRD patterns of the healing products formed in mortar specimens containing different supplementary cementitious materials (SCMs) compared to the reference. No significant differences were found for the diffraction peaks of all samples. Calcite was detected as the major crystal healing product for all samples. SEM observations indicated that micron-sized calcite crystals with a typical rhombohedral morphology were 
closely packed together, as shown in Figure 10. In addition, the TG/DTG curves of the healing products in the crack mouth are shown in Figure 11. An obvious weight loss in the range of $600-800{ }^{\circ} \mathrm{C}$ was found, and the corresponding peaks related to the decomposition of calcium carbonate at about $750{ }^{\circ} \mathrm{C}$ were observed in all samples. The weight losses between 600 and $800{ }^{\circ} \mathrm{C}$ of reference, 20FA and 20BFS were $41.12 \%, 40.93 \%$ and $40.45 \%$, respectively. According to the thermal decomposition equation of calcium carbonate, the percentages of calcium carbonate in the healing products from reference, 20FA and 20BFS were calculated as $93.46 \%, 93.03 \%$, and $91.94 \%$. The results of TG analysis were consistent with XRD and SEM, indicating that the major healing product from the healed surface cracks of the referenced specimens and the specimens containing different supplementary cementitious materials (SCMs) was calcium carbonate.

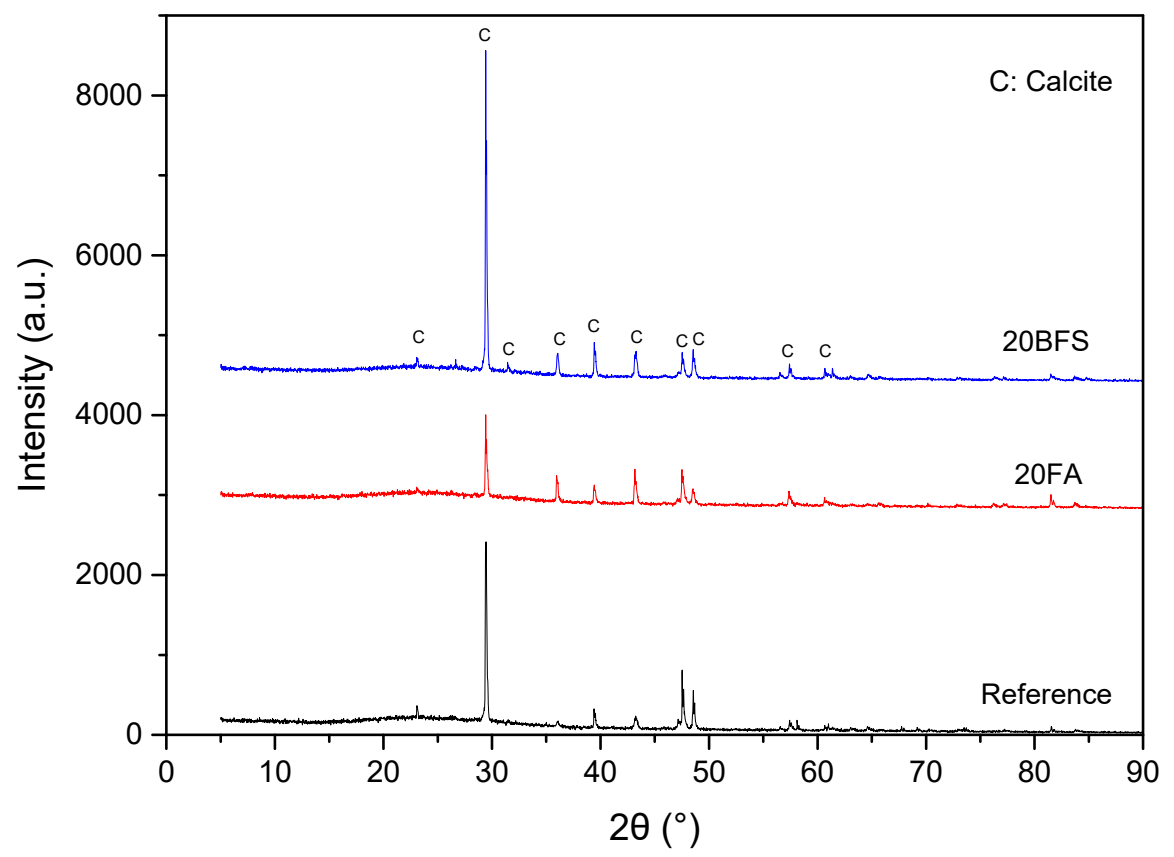

Figure 9. X-ray diffraction (XRD) patterns of the healing products in the mouths of the cracks.

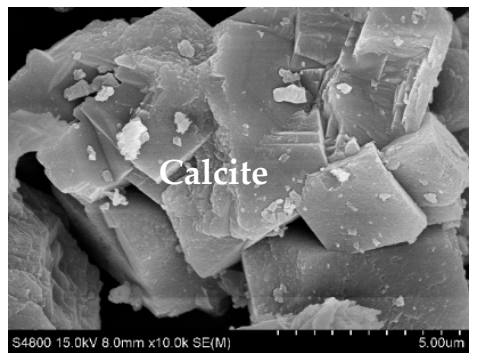

(a)

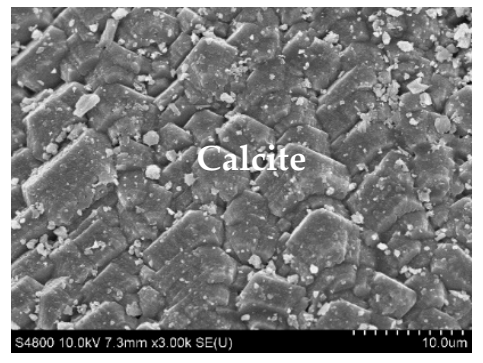

(b)

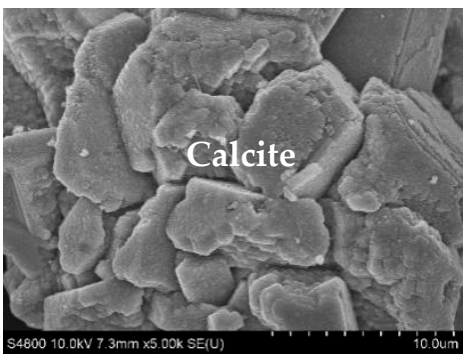

(c)

Figure 10. Scanning electron microscopic (SEM) observations of the healing products in the mouths of the cracks: (a) Reference; (b) 20FA; (c) 20BFS. 


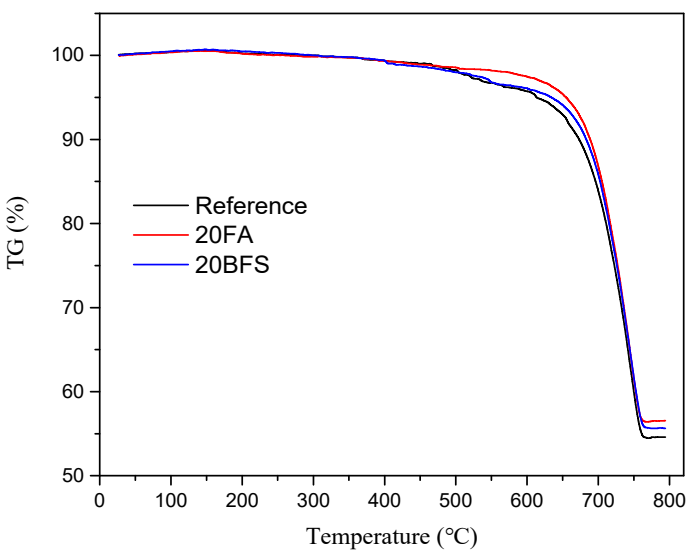

(a)

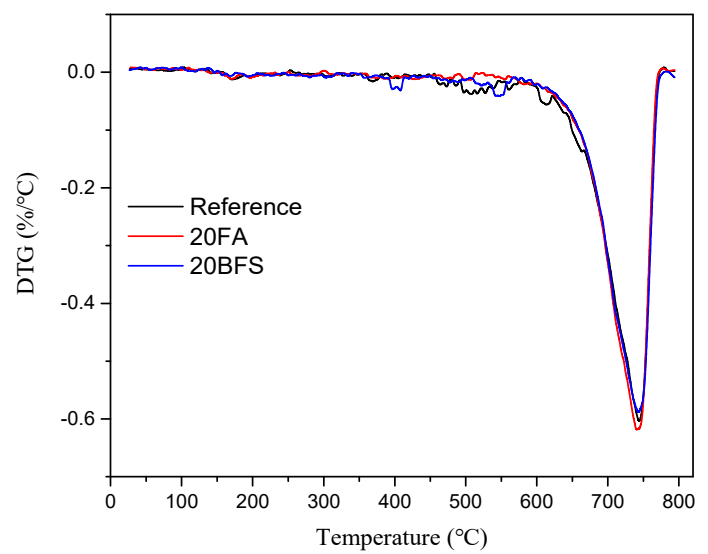

(b)

Figure 11. Thermogravimetric (TG/DTG) curves of the healing products in the mouths of the cracks: (a) TG curves; (b) DTG curves.

\section{Conclusions}

The effects of curing conditions and supplementary cementitious materials on the autogenous self-healing of early age cracks in cement mortar were investigated. Three curing conditions (standard curing, wet-dry cycles and incubated in water) and two SCMs (FA and BFS) with various contents (cement replacement ratio at $0 \%, 20 \%$, and $40 \%$ ) were considered. Autogenous crack self-healing efficiency of mortar specimens was evaluated by performing a visual observation and a water permeability test. Moreover, XRD, SEM and TG/DTG were conducted to characterize the healing products. Based on the experimental results, the following conclusions can be drawn:

(1) The presence of water is essential for autogenous self-healing of early age cracks in cement mortar. Crack self-healing efficiency was highest in specimens incubated in water. However, no significant self-healing occurred in specimens exposed to standard curing. For wet-dry cycles, a longer healing time was needed to obtain good self-healing compared to those samples incubated in water.

(2) SCMs type and content significantly affected the autogenous self-healing ability of early age cracks. Crack self-healing efficiency for early age cracks decreased with the increase in FA and BFS content. BFS mortars exhibited better recovery of water penetration resistance compared to the reference and FA mortars. Almost the same regaining of water tightness and a lower crack-healing ratio after healing for 28 days in FA mortars were observed in comparison to the reference.

(3) The major healing product in surface cracks of specimens with and without SCMs was micron-sized calcite crystals with a typical rhombohedral morphology.

Author Contributions: Conceptualization, M.L. and H.H.; methodology, M.L., K.J. and J.B.; investigation, M.L., K.J. and J.B.; data curation, K.J. and Z.D.; writing-original draft preparation, M.L.; writing-review and editing, M.L. and H.H.; visualization, J.B. and Z.D.; supervision, M.L., D.Y., Y.G. and H.H. All authors have read and agreed to the published version of the manuscript.

Funding: This research was funded by the National Natural Science Foundation of China (No. 51808483), the Natural Science Foundation of Jiangsu Province (No. BK20180930), the Opening Project of State Key Laboratory of Green Building Materials, and the Opening Fund of Jiangsu Key Laboratory of Construction Materials (No. CM2018-10).

Institutional Review Board Statement: Not applicable.

Informed Consent Statement: Not applicable.

Data Availability Statement: The data presented in this study are available on request from the corresponding authors. 
Conflicts of Interest: The authors declare no conflict of interest.

\section{References}

1. Wang, K.; Jansen, D.C.; Shah, S.P. Permeability study of cracked concrete. Cem. Concr. Res. 1997, 27, 381-393. [CrossRef]

2. Zhang, P.; Wittmann, F.H.; Vogel, M.; Müller, H.S.; Zhao, T. Influence of freeze-thaw cycles on capillary absorption and chloride penetration into concrete. Cem. Concr. Res. 2017, 100, 60-67. [CrossRef]

3. Huseien, G.F.; Shah, K.W.; Sam, A.R.M. Sustainability of nanomaterials based self-healing concrete: An all-inclusive insight. J. Build. Eng. 2019, 23, 155-171. [CrossRef]

4. Wang, Y.R.; Cao, Y.; Zhang, P.; Ma, Y.; Zhao, T.; Wang, H.; Zhang, Z. Water absorption and chloride diffusivity of concrete under the coupling effect of uniaxial compressive load and freeze-thaw cycles. Constr. Build. Mater. 2019, 209, 566-576. [CrossRef]

5. Lauer, K.R.; Slate, F.O. Autogenous healing of cement paste. ACI Mater. J. 1956, 52, 1083-1098. [CrossRef]

6. Ter Heide, N. Crack Healing in Hydrating Concrete. Master's Thesis, Delft University of Technology, Delft, The Netherlands, 2005.

7. Huang, H.; Ye, G.; Damidot, D. Characterization and quantification of self-healing behaviors of microcracks due to further hydration in cement paste. Cem. Concr. Res. 2013, 52, 71-81. [CrossRef]

8. Reinhardt, H.W.; Jooss, M. Permeability and self-healing of cracked concrete as a function of temperature and crack width. Cem. Concr. Res. 2003, 33, 981-985. [CrossRef]

9. Rooij, M.; van Tittelboom, K.; Belie, N.; Schlangen, E. (Eds.) Self-Healing Phenomena in Cement-Based Materials: State-of-the-Art Report of RILEM Technical Committee 221-SHC. Self-Healing Phenomena in Cement-Based Materials; Springer: Berlin/Heidelberg, Germany, 2013.

10. Li, W.; Dong, B.; Yang, Z.; Xu, J.; Chen, Q.; Li, H.; Xing, F.; Jiang, Z. Recent Advances in Intrinsic Self-Healing Cementitious Materials. Adv. Mater. 2018, 30, 1705679. [CrossRef]

11. Van Tittelboom, K.; De Belie, N.; Van Loo, D.; Jacobs, P. Self-healing efficiency of cementitious materials containing tubular capsules filled with healing agent. Cem. Concr. Compos. 2011, 33, 497-505. [CrossRef]

12. Wiktor, V.; Jonkers, H.M. Quantification of crack-healing in novel bacteria-based self-healing concrete. Cem. Concr. Compos. 2011, 33, 763-770. [CrossRef]

13. Wang, J.Y.; Soens, H.; Verstraete, W.; De Belie, N. Self-healing concrete by use of microencapsulated bacterial spores. Cem. Concr. Res. 2014, 56, 139-152. [CrossRef]

14. Luo, M.; Qian, C.-X.; Li, R.-Y. Factors affecting crack repairing capacity of bacteria-based self-healing concrete. Constr. Build. Mater. 2015, 87, 1-7. [CrossRef]

15. Xu, J.; Wang, X.Z. Self-healing of concrete cracks by use of bacteria-containing low alkali cementitious material. Constr. Build. Mater. 2018, 167, 1-14. [CrossRef]

16. Sisomphon, K.; Copuroglu, O.; Koenders, E.A.B. Self-healing of surface cracks in mortars with expansive additive and crystalline additive. Cem. Concr. Compos. 2012, 34, 566-574. [CrossRef]

17. Alghamri, R.; Kanellopoulos, A.; Litina, C.; Al-Tabbaa, A. Preparation and polymeric encapsulation of powder mineral pellets for self-healing cement based materials. Constr. Build. Mater. 2018, 186, 247-262. [CrossRef]

18. Van Tittelboom, K.; Gruyaert, E.; Rahier, H.; De Belie, N. Influence of mix composition on the extent of autogenous crack healing by continued hydration or calcium carbonate formation. Constr. Build. Mater. 2012, 37, 349-359. [CrossRef]

19. Jiang, Z.; Li, W.; Yuan, Z. Influence of mineral additives and environmental conditions on the self-healing capabilities of cementitious materials. Cem. Concr. Compos. 2015, 57, 116-127. [CrossRef]

20. Yang, Y.G.; Yang, E.H.; Li, V.C. Autogenous healing of engineered cementitious composites at early age. Cem. Concr. Res. 2011, 41, 176-183. [CrossRef]

21. Zhang, Z.; Qian, S.; Ma, H. Investigating mechanical properties and self-healing behavior of micro-cracked ECC with different volume of fly ash. Constr. Build. Mater. 2014, 52, 17-23. [CrossRef]

22. Saillio, M.; Baroghel-Bouny, V.; Pradelle, S.; Bertin, M.; Vincent, J.; d'Espinose de Lacaillerie, J.B. Effect of supplementary cementitious materials on carbonation of cement pastes. Cement Concr. Res. 2021, 142, 106358. [CrossRef]

23. Haridharan, M.K.; Matheswaran, S.; Murali, G.; Abid, S.R.; Fediuk, R.; Mugahed Amran, Y.H.; Abdelgader, H.S. Impact response of two-layered grouted aggregate fibrous concrete composite under falling mass impact. Constr. Build. Mater. 2020, 263, 120628. [CrossRef]

24. Sahmaran, M.; Yildirim, G.; Erdem, T.K. Self-healing capability of cementitious composites incorporating different supplementary cementitious materials. Cem. Concr. Compos. 2012, 35, 89-101. [CrossRef]

25. Huang, H.; Ye, G.; Damidot, D. Effect of blast furnace slag on self-healing of microcracks in cementitious materials. Cem. Concr. Res. 2014, 60, 68-82. [CrossRef]

26. Qiu, J.; Tan, H.S.; Yang, E.-H. Coupled effects of crack width, slag content, and conditioning alkalinity on autogenous healing of engineered cementitious composites. Cem. Concr. Compos. 2016, 73, 203-212. [CrossRef]

27. Darquennes, A.; Olivier, K.; Benboudjema, F.; Gagné, R. Early-age self-healing of cementitious materials containing ground granulated blast-furnace slag under water curing. J. Adv. Concr. Technol. 2016, 14, 717-727.

28. Şahmaran, M.; Keskin, S.B.; Ozerkan, G.; Yaman, I.O. Self-healing of mechanically-loaded self consolidating concretes with high volumes of fly ash. Cem. Concr. Compos. 2008, 30, 872-879. [CrossRef] 
29. Termkhajornkit, P.; Nawa, T.; Yamashiro, Y.; Saito, T. Self-healing ability of fly ash-cement systems. Cem. Concr. Compos. 2009, 31, 195-203. [CrossRef]

30. Parashar, A.; Bishnoi, S. A comparison of test methods to assess the strength potential of plain and blended supplementary cementitious materials. Constr. Build. Mater. 2020, 256, 119292. [CrossRef]

31. Liu, H.; Huang, H.; Wu, X.; Peng, H.; Li, Z.; He, J.; Yu, Q. Effects of external multi-ions and wet-dry cycles in a marine environment on autogenous self-healing of cracks in cement paste. Cem. Concr. Res. 2019, 120, 198-206. [CrossRef]

32. Suleiman, A.R.; Nehdi, M.L. Effect of environmental exposure on autogenous self-healing of cracked cement-based materials. Cem. Concr. Res. 2018, 111, 197-208. [CrossRef]

33. Zhang, W.; Zheng, Q.; Ashour, A.; Han, B. Self-healing cement concrete composites for resilient infrastructures: A review. Compos. Part B Eng. 2020, 189, 107892. [CrossRef]

34. Luo, M.; Bai, J.Q.; Jing, K.; Ding, Z.Q.; Yang, D.Y.; Qian, C.X. Self-healing of early-age cracks in cement mortars with artificial functional aggregates. Constr. Build. Mater. 2021, 272, 121846. [CrossRef] 